\title{
1.7 INNOVATIVENESS AS THE MAIN PURPOSE OF MANAGEMENT AND ORGANIZATION SUCCESSFULNESS
}

\begin{abstract}
Summary: Many literatures have sourced the best practice for innovativeness by recognizing that it consist a structural formation while to some literatures, it is a cognitive foundations. All in all, emphasize is to show how organization can resist and still be profitable in today's hostile environments and huge challenges by employing the use of technological and knowledge platform, which means that innovative organization are those that can respond and shape its external environmental stimulus. Some authors described polar typologies and characterized organization into two structures: 'mechanistic in nature', which is rigid and hierarchical and 'organic in nature', which is more flexible and can rapidly change to innovation. However, Mintzberg (1979) suggested a design that would match the organization situation. He developed some parameters of factor analysis, which means that effective structuring requires consistency of design parameters and contingency factors.

The paper therefore would present innovativeness as organizational structures and management encapsulation. The study would examine different types of management and organization structures that could lead to innovativeness and different forms of organization contingencies to be innovative, relative to both evolutionary and revolutionary technological changes. The study would use interviews and questionnaires from managers and employees of Vodafone Hungary to check the importance of innovation structuring. At end, the study tried to prove that structures of the management and organization generate innovativeness.
\end{abstract}

Keywords: innovation, strategy and structures, management style, organization

\section{INTRODUCTION}

In recent years, organizations and management has stressed the need of innovation-driving conceptualization methodology as a crucial part of competitive advantage. Many social scientists amongst them are Mintzberg (1979), Chandler (1962 and 1998) and Lazonick (1990), have sourced the best practice for innovativeness by recognizing that it consist a structural formation and a cognitive foundation. All in all, emphasize is to show how organization can resist and still be profitable in today's hostile environments and huge challenges by employing the use of technological and knowledge platform, which means that innovative organization are those that can respond and shape its external environmental stimulus.

Innovativeness encompasses the ability to nurture and use natural creativity, develop new ideas and bring them to life (Mullins, 2010, p. 802). The author wrote that organizations and management should identify their clusters through the resources which diverse cultures plays in to help enhancement of its capability through what she called "Clusters of opportunities". They are:

- Organizational agility or liveliness will ensure that organizations have and utilize the inherent potential and energy of their employees.

- Organizational clarity is recognizing what is and what is not important in relation to the business context. This is about decision-making, sound judgment and clarity about core organizational issues.

- Organizational flexibility is the ability to adapt and change at the rate of change required. 
- Organizational genuineness is about operating in line with values and innate wisdom and common sense of mankind that grows from different cultural orientations and dimensions.

- Organizational openness allows for fluid of different cultural interactions within and between the inner world of the organization and its outer world.

Integration of different cultural-role-point at the heart of the organization could help attract these clusters of opportunities which are equals to innovative organization or team.

When we are talking about innovativeness, we are expressing knowledge-based conversion that results to creativity. The knowledge are codified (explicit) and tacit (implicit). Codified knowledge is transformed into information, which can be transmitted through information infrastructures. Nevertheless, tacit knowledge cannot be easily transferred because it has not been put in an explicit 'information' form. However, to convert and transmit tacit knowledge, which is always in form of "unknown" knowledge such as shared beliefs and ways of interpretation. To transfer this kind of knowledge is through social interaction as in apprenticeship or working/group solving relationships. It implies that transfer is sensitive to a social context. It means the more social interaction and relationship are maintained across different cultural group, the higher the innovativeness to solve problems and skills to achieve creativity.

In order to comprehend innovation, we need to understand organization behaviour and management style. The big questions the study wish to ask are:

- What is the organizational behaviour?

- Which behaviour can lead to innovativeness?

- What are the management styles that can aid innovation?

- What are the consequences of flexible and or rigid management style towards innovativeness?

\subsection{OBJECTIVES OF THE STUDY}

From the management and organizational success perspective, there are two main elements namely, process of management and organizational context and people course of action (Mullins, 2010). The first element is what Mullins called the psychological approach which is basically the people-organization contractual terms and or relationship management.

The second element structural styling and result oriented. There are many behavioural influences such as the individual, the group, the organization and the environment.

So, the specific objectives of the paper are: to examine how organization and management coordination could create innovativeness; to identify different organizational behaviours and management styling that could span innovation; to show which of the school of thoughts and style fits into different innovative approaches; finally, to draw conclusions that innovation is a byproduct of organization and management technique.

The paper therefore would want to prove that successful innovation is a functionality of organizational behaviour and management styling.

\section{LITERATURE REVIEW}

\subsection{ORGANIZATIONAL INNOVATIVENESS}

These days of tight competition among organization create the willingness to embrace culture of innovation. The success and failure of atypical organization is the culture it apprehends and its operation and management style. It is imperative that employees live and 
work within the four walls of culture be it individual, group or corporate cultures; we are bounded and breathe in cultures.

There are many definition of organization culture found in literatures, but interestingly has being very different from viewpoints of anthropologist, sociologist, psychologist, politicians and management researchers. Hoechlin (1995) defined culture as a shared system of meanings. She continued to say that culture dictates what groups of people and organization pay attention to. It guides how the world is perceived, how the self is experienced, and how the life itself is organized. Rugman and Collinson (2009) defined culture as the sum total of the beliefs, rules, techniques, institutions and artifacts that characterize human populations.

Hofstede (1980 and 1991) called it the collective programming of the mind. Schneider and Barsoux (2003) defined culture as shared patterns of behaviour. According to the authors, culture serves as a lens through which we perceive the other, organize out operation, and design the management style and coordination. We tend to use the organization culture as a preference point to evaluate the other and benchmark our output.

The overall determinant of organization culture is the management and strategy put in place. From management perspective, innovativeness can be achieved through a well functional management style and structure that support creativity and flexibility to the robust nature of the world of globalization. According to Mullins (2010), there are many designs and structures namely: simple structure, machine bureaucracy, professional bureaucracy, divisionalised form and adhocracy. Most of these structures are rigid and hierarchical, most are flexible, and can rapidly change to innovative solution. The bureaucratic archetypes are stiff nosed into rigidity, which makes it hard to cope in ever changing environment. However, both classifications are neither wrong nor right but the contingency around an organization is the main factor to be considered.

Therefore, it is the responsibility of the management to know how the industry it is into are fairing. That is, how organization adapt on the different scenarios including market, technical, economic and scientific matters a lot to its adaptability.

Organizational structure as both cause and effect of managerial strategic choice in response to market opportunities is the way many micro-economists view it. This is from two variables mainly strategy and structure and both are interrelated and are of people-leadinnovation. The purpose of strategy is mainly to have a pattern of major objectives, goals and essential policies and defined very accurately and in a constant manner. While structure is the division and coordination of tasks among members of the organization to achieve goals and objectives, it brings into organization new ways of doing things, which is basically „innovation” (Mullin, 2010). There are mainly two variables that determine the competitive advantage (innovative solution) of a business enterprise: governance modes and organization cultures and values. These are powerfully influence to its rate and direction towards innovative activities.

\subsection{LEADERSHIP, RELATIONSHIP AND CULTURAL STYLES}

In practice, the activities of an organization and the role of management cannot be isolated neatly into categories life. As a principle, people are the key resources of any organization. But since we are talking about organization culture, the employees must have the ability to learn and believe on the culture spelled out in the mission, vision and guiding principles, with or without compromising their individual cultures.

Organizational culture is express in the mission, vision and guiding principles of the firm, in other words "corporate strategy". As a consequence, gives rise to leadership style and relationship based within and outside the firm, practically viewed as a winning tactics for organization to achieve growth, market penetration opportunities and industry leadership. 
Every organization has a corporate strategy it must follow to achieve a cohesive work environment and goals. Corporate strategy is concerned with the overall scope of an organization and how value will be added to the different parts of the organization (Gerry et al. 2008, p. 7).

Organizational culture (leadership style, relationship style and cultural style) and its ability to generate innovativeness relate to the symbolic dimension of formality and informality, also to the extent the organization can capture the knowledge of the employees. According to Mullins (2010, p. 4), the behaviour of people and management style cannot be studied in isolation. It is necessary to understand interrelationships with other variables that together comprise the total organization such as formal aspect (overt) and behavioural aspect (covert). Organizational culture leads to organizational learning and innovation modelling within the organization. Literatures mainly classified the forms into two types namely: "J-form" and "adhocracy" (Lam, 2000 and 2002). J-form is the organization that exploits learning to achieve collective competencies and problem-solving platform (organizational community that nurture tacit and radical knowledge that emphasize continuous improvement across all functions) while adhocracy puts emphasizes on individual specialization (an organic and adaptive format that foster ad-hoc and specialist project team to solve problems) There are concerns when team member leaves the organization, and supposedly, the adoption of adhocracy by large corporations proved difficult to sustain on this ever changing environment.

Both forms have strong innovative capacities but diverge in knowledge configurations, patterns and types of competencies produced. Researchers argue that the factor is an outcome of a passive environmental selection process while some researchers argue that it is a product of managerial action and strategic choice in shaping the organizational change. These however become ambiguous in nature as researchers treat organizational change as a technological triggering response. In general, many changes are tendencies of internal organizational dynamics, actor cognition and behavioural conditions.

The view of many researchers suggests that long-term key of organization relies on its ability to build on existing competencies while simultaneously exploring new possibilities to achieve competitive advantage over competitors. This could be interpreted in this form that organization should create the capacity for learning, values, interest and culture in shaping organizational change and innovation through leadership competency.

Leadership is one of the key factors that shape employees behaviours, thinking and feelings and also the ability to share knowledge that would be very useful to the organization. Leadership behaviourism always comes from different forces within and outside the organization. If the leadership style creates trust, then it can apprehend a sort of ,,collective memory" of the employees which is basically what Hofstede called „culture”. It can either be a "stock" of knowledge stored as hard data or represent knowledge in a state of "flow" emerging from interaction. Both individuals and organizations are learning entities. All learning activities, however, take place in a social context, and it is the nature and boundaries of the context that make a difference to learning outcomes. In broad context, leadership could play out in the following forms.

Autocratic leadership style: an extreme form of transactional leadership, where leaders have absolute power over their workers or team. Staff and team members have little opportunity to make suggestions, even if these would be in the team's or the organization's best interest. Most people tend to resent being treated like this. Therefore, autocratic leadership usually leads to high levels of absenteeism and staff turnover. For some routine and unskilled jobs, the style can remain effective because the advantages of control may outweigh the disadvantages.

Bureaucratic leadership style: follow rules rigorously, and ensure that their staff follows procedures precisely. This is a very appropriate style for work involving serious safety risks 
such as working with machinery, with toxic substances, or at dangerous heights or where large sums of money are involved such as handling cash.

Charismatic leadership style: can seem similar to transformational leadership, because these leaders inspire lots of enthusiasm in their teams and are very energetic in driving others forward. However, charismatic leaders can tend to believe more in themselves than in their teams, and this creates a risk that a project, or even an entire organization, might collapse if the leader leaves. In the eyes of the followers, success is directly connected to the presence of the charismatic leader. As such, charismatic leadership carries great responsibility, and it needs a long-term commitment from the leader.

Participative leadership style: although participative leaders make the final decisions, they invite other members of the team to contribute to the decision-making process. This not only increases job satisfaction by involving team members, but it also helps to develop people's skills. Team members feel in control of their own destiny, so they're motivated to work hard by more than just a financial reward. Because participation takes time, this approach can take more time, but often the end result is better. The approach can be most suitable when working as a team is essential, and when quality is more important than speed to market or productivity.

Laissez-faire leadership style: this is a French phrase means „leave it be,” and it's used to describe leaders who leave their team members to work on their own. It can be effective if the leader monitors what is being achieved and communicates this back to the team regularly. Most often, laissez-faire leadership is effective when individual team members are very experienced and skilled self-starters. Unfortunately, this type of leadership can also occur when managers do not apply sufficient control.

People-oriented leadership or relations-oriented leadership style: this is the opposite of task-oriented leadership. With people-oriented leadership, leaders are totally focused on organizing, supporting, and developing the people in their teams. It is a participative style, and it tends to encourage good teamwork and creative collaboration.

Task-oriented leadership style: focus only on getting the job done, and they can be quite autocratic. They actively define the work and the roles required, put structures in place, plan, organize, and monitor. However, because task-oriented leaders do not tend to think much about the well-being of their teams, this approach can suffer many of the flaws of autocratic leadership, with difficulties in motivating and retaining staff.

Servant leadership style: describes a leader who is often not formally recognized as such. When someone, at any level within an organization, leads simply by meeting the needs of the team, he or she is described as a „servant leader.” In many ways, servant leadership is a form of democratic leadership, because the whole team tends to be involved in decision-making.

Transactional leadership style: this style of leadership starts with the idea that team members agree to obey their leader totally when they accept a job. The „transaction" is usually the organization paying the team members in return for their effort and compliance. The leader has a right to ,punish” team members if their work doesn't meet the predetermined standard. Team members can do little to improve their job satisfaction under transactional leadership. The leader could give team members some control of their income/reward by using incentives that encourage even higher standards or greater productivity. Alternatively, a transactional leader could practice „management by exception” - rather than rewarding better work, the leader could take corrective action if the required standards are not met. Transactional leadership is really a type of management, not a true leadership style, because the focus is on short-term tasks. It has serious limitations for knowledge-based or creative work.

Transformational leadership style: people with this leadership style are true leaders who inspire their teams constantly with a shared vision of the future. While this leader's 
enthusiasm is often passed onto the team, he or she can need to be supported by „detail people." That is why, in many organizations, both transactional and transformational leadership is needed. The transactional leaders or managers ensure that routine work is done reliably, while the transformational leaders look after initiatives that add value.

As leaders of the organization converge to solve problems, they develop different relationships of different tones and values. The relativity brings in innovative solutions. Gerry and his co-authors, Scholes and Whittington (Gerry et al pg. 161) described sources and indicators of power that could be potential innovative solution within an organization and for external stakeholders (Table 1).

Table1: Power and Control within and outside the organization culture

\begin{tabular}{|l|l|}
\hline \multicolumn{1}{|c|}{ Sources within organization } & Indicators within organization \\
\hline Hierarchy (formal power) e.g. autocratic decision making & Status \\
\hline Influence (informal power) e.g. charismatic leadership & Claim on resources \\
\hline Control of strategic resources e.g. strategic products & Representation \\
\hline Possession of knowledge and skills e.g. computer specialists & Symbols \\
\hline Control of the human environment e.g. negotiating skills & \\
\hline $\begin{array}{l}\text { Involvement in strategy implementation e.g. by exercising } \\
\text { discretion }\end{array}$ & \\
\hline Sources for external stakeholders & $\begin{array}{l}\text { Indicators for external } \\
\text { stakeholders }\end{array}$ \\
\hline Control of strategic resources e.g. materials, labour, money & Status \\
\hline $\begin{array}{l}\text { Involvement in strategy implementation e.g. distribution outlets, } \\
\text { agents }\end{array}$ & Resources dependence \\
\hline Possession of knowledge and skills e.g. subcontractors, partners & Negotiating arrangements \\
\hline Through internal links e.g. informal influence & Symbols \\
\hline
\end{tabular}

Source: Own creation, based on Gerry et al., 2008

Looking at power within the organization would be shared unequally between various stakeholders. For the purpose of this discussion, power can be a source of innovative solution and of non-solution too. Power is defined by Gerry et al (p. 160) as the ability of individuals or groups to persuade and induce or coerce others into following certain courses of action. This is a mechanism by which one set of expectations will influence strategic development or seek compromise with others. Power sets the framework of culture, leading to collective memory. Culture strength by Taylor Cox pinpointed the combination of the extent to which norms and values within the organization are clearly defined and are rigorously adopted. Hoecklin (1997) listed six dimensions of organization culture namely: motivation, relationship, identity, communication, control, and conduct. These dimensions are in line with Kirton and Greene and Taylor Cox versions.

However, organizations that excel at leveraging their know-how (people) in a systematic way will a Knowledge Management strategy, corresponding architecture, and deploying effective knowledge systems, through formal and informal relationship format. Key to leveraging the knowledge of an organization is providing insight, thought leadership and context to those who have the most at stake in generating and using organizational knowledge. In order to generate this pragmatic strategy (innovation), it is important to provide a framework through leadership structure, well defined strategy and knowledge capturing tools that could disseminate to be ,innovation”.

Innovation is possible when organizational culture spells out very well in the mission statement of the organization. The mission serves as organizational learning and innovation model that could develop to be a culture. During this period, the leadership is formed based 
on the culture of the organization that determine the internal and external relationship of the organization. Successful management of this virtuous circle could spark innovative solutions, with high economic values. Frank and Bernanke (2009) in the book "thinking like an economist" argue that an action should be taken if, but only if, its benefit is at least as great as its cost. Therefore, leaders benefit from different engaged relationships. After all, what triggers the engagement is to benefit, which is obvious an economic system. Schumpeter (1911) argue that innovation with the introduction of what he calls 'new productive combinations', consisting in a different combination of existing means of production with the aim of producing a new good, or a new production method, or opening up a new market, or securing a new source of supplies of raw materials and semi-finished items, or reorganizing some industry by introducing new forms of market and new forms of competition and establishing and or re-forcing new cultural aptitude.

Overall, the economic system of the virtuous circle becomes very vital for innovative solutions. Generative relationships require particular places and entities - such as user groups, fairs and commercial networks, professional organizations, and information systems - that perform the important function of scaffolding structures, that is, they support the system of interactions and the market.

\section{RESERACH METHODOLOGY}

The strategy is to gain a good understanding of the context of the research and the process that was enacted to analyze the theory appropriately. According to Saunders et al. (2003 p.83) a case study strategy can be of particular interest if that is the aim.

Jankowicz (2005) wrote that survey method draws most of its data from the present. This is surveying people to establish their views of what they think, believe, value, or feel through interviews and questionnaires. Survey method will help discover these views for their sake and to support an argument of the research work and generalise conclusions more widely. Jankowicz views survey method as perfect method to carry out research work at any level.

Since this topic is connected to innovation and management style (organization strategy and structure), it was right to obtain information from people who are on the management level of the organization. Obviously, the number of people on that level is minimal, only three people was reached for interview. For confidentiality sake, the study would present the company name, but the managers' name as anonymous. The name of the company is Vodafone Hungary $\mathrm{Kft}$ and the names of managers withheld. The questions the study presented have two dimensions namely: leadership style and organizational structure.

Leadership style is the way the management leads the people in organization. The study wants to examine three key elements of decision-making process in the organization. There are three basic styles:

- autocratic: making decision without consultation

- democratic: making decision with input generated during consultation process

- laissez-faire: allowing decision to be made by people in the team

Organizational structure that has two variables, namely: strategy and structure.

- strategy: as defined by the McKinsey 7-S Framework has the following variables: structure, strategy, people, management style, systems and procedures, guiding concepts and shared values (that is culture), and the present and hoped-for corporate strengths and skills.

- structure: as a perspective of social and organizational behaviour in understanding the relationship between formal and informal aspects of organization. 


\subsection{DATA COLLECTION AND ANALYSIS}

The paper used two methods of testing, interview and questionnaire to compare the literature. With the interview, three managers were interviewed at the head office of Vodafone. One woman and two men of them were around 35 and 55 years old. Three questions were asked and results listed below.

The main purpose of the interview was to get a clearer view on innovative, organization strategy and structure and management style. This could be achieved making sure the right questions are being asked, using appropriate research techniques and controls and finally presenting the research findings in a clear, comprehensive format that leads to action.

Interview Result: the managers were interviewed separately and classified into three groups (Group 1, Group 2 and Group 3), below questions were asked and their answers are presented on the table according to the group.

- What drives innovation in your company?

- What of sort of manager are you?

- Do you consider strategy and structure as main focus to achieve innovation?

Table 2: Analysis of the first interviewed manager group

\begin{tabular}{|c|l|l|}
\hline $\mathbf{1}$ & First question & People and technology deployment and coordination \\
\hline & Second question & democratic \\
\hline & Third question & Yes because it set the direction \\
\hline
\end{tabular}

Source: Own creation

Table 3: Analysis of the second interviewed manager group

\begin{tabular}{|c|l|l|}
\hline $\mathbf{2}$ & First question & Ability of people to work and think freely \\
\hline & Second question & Democratic and laissez faire \\
\hline & Third question & Yes, it should be spelled out clearly in order to achieve innovation \\
\hline
\end{tabular}

Source: Own creation

Table 4: Analysis of the third interviewed manager group

\begin{tabular}{|c|l|l|}
\hline $\mathbf{3}$ & First question & Company ability to understand the workers and assign suitable roles \\
\hline & Second question & Democratic and autocratic \\
\hline & Third question & $\begin{array}{l}\text { Yes, should be dedicated to achieve innovativeness and competitive } \\
\text { advantage }\end{array}$ \\
\hline
\end{tabular}

Source: Own creation

To conclude, the questions brought mixed reactions and answers from the managers. All confirmed that for innovation to flourish in organization, needs freedom of employees, clear roles in order the employees to understand the business processes and above all a flexible management style. This confirms that management styling, strategy setting and structure are keys of innovativeness organization.

With the second method, questionnaires were distributed inside the Vodafone Consumer Management Unit (CMU). This department alone employs more than 350 people. CMU departments are technology deployment, project management, terminals and consumer care centre. CMU is the only Vodafone unit that interfaces with all internal and external departments. Therefore, CMU seems the right department to investigate what people feel concerning the management styling and people coordination, its effect to achieve innovativeness and successfulness of the company.

The survey questionnaires included three questions and due to Vodafone information sharing policy, only 20 questionnaires were distributed. All were filled because I was sitting 
beside the people to collect the papers immediately. The questionnaires were in English and the questions were composed of 'open-ended type' with available answers (a-d). The questions were similar to what the managers were asked. This was done to validate what they all think that can help reproduce innovative culture in Vodafone. The following questions were asked to the employees

- What do you think drives innovation in your company?

Answer: (a) good people management (b) company strategy (c) good team work (d) good pay

- What of sort of employee are you?

Answer: (a) think creatively with help of management (b) think creatively without help of management (c) can-do-attitude person (d) can-do-only with team support

- Do you consider strategy and structure as main focus to achieve innovation?

Answer: (a) yes, it does matter (b) no, it does not matter (c) maybe (d) do not know

Table 5: Analysis of the questionnaires

\begin{tabular}{|l|l|c|}
\hline Question 1 & What do you think drives innovation in your company? & Rate \\
\hline & good people management & 5 \\
\hline & company strategy & 2 \\
\hline & good team work & 4 \\
\hline Question 2 & What of sort of employee are you? & 9 \\
\hline & think creatively with help of management & Rate \\
\hline & think creatively without help of management & 5 \\
\hline & can-do-attitude person & 2 \\
\hline & can-do-only with team support & 10 \\
\hline Question 3 & Do you consider strategy and structure as main focus to achieve innovation? & Rate \\
\hline & yes, it does matter & 9 \\
\hline & no, it does not matter & 2 \\
\hline & maybe & 6 \\
\hline & do not know & 3 \\
\hline
\end{tabular}

Source: Own creation

When you compare answers from the interview and questionnaires, it is very surprising. It is interesting to see how employees themselves view innovativeness and management. Managers on their part view it differently. Their view is in line with the company strategy and structure. The employees view is very much self centered. Their view is what I term as „own” perspective. You can see on the table that „, good pay” and ,can-do-attitude” received higher marks.

I can acknowledge the higher marks are very good for a functional and flexible management style to achieve innovativeness. Meaning that with very good coordination, a manager, can extract the „own” perspective of the employee to achieve innovation. Managerial view point and „own” perspective are intertwined with leadership, relationship and cultural style and management. These are basically the key elements to achieve innovation. Therefore, the assumption of a successful innovativeness was well integrated from the response gathered.

The employees of Vodafone Hungary believe that if you pay them good, they can give their best to the organization. However, good pay and can-do-attitude comes from the strategy 
and structure of the organization. The employees' answers are in line with the literature where authors canvass issues of dynamics on innovativeness as organizational structures and management encapsulation. The notion prompt authors such as Mullins to identify what she called "Clusters of opportunities". Mullins wrote that organizations and management should identify their clusters through the resources, which diverse cultures plays in to help enhancement of its capability. She also wrote that innovativeness encompasses the ability to nurture and use natural creativity, develop new ideas and bring them to life.

On the event, Mullins identified two main elements such as process of management and organizational context and people course of action which were in line with the survey. However, Schneider and Barsoux argued that organization culture as a preference point to evaluate the other and benchmark our output. Which means that no matter how the management and leadership of an organization is, what matters most is the output. The contrary argument of Schneider and Barsoux does not consider the answers from the employees „own” perspective but rather more focus was on managerial viewpoint. At some point too, the author puts culture at the heart core which boils down somehow to employees „own” perspective.

\section{CONCLUSION}

As organizations strife in their quest for growth and profit making strategy, the managers are faced with numerous problems that are associated with the innovative strategy. Also, as the world becomes a global Market place, organizations needs innovation to explore new markets, increase profits and achieve competitive advantage.

The study focused on the innovation as the driving force of successful company; however innovation is a function of robust management style that can face the drum beat of the modern days business climate which is a mix of leadership, relationship and cultural dimensions. These are seen in the coordination and operations of the organization. The management needs to properly integrate these dimensions into all areas of operations and make sure all stakeholders are involved in drafting these dimensions; otherwise it can have direct or indirect cost on the organization. Because innovation and management styling has many facets, it worth studying and understanding to enable a company tap the potential of its employees and to achieve its objective and goal. Innovation is a direct link of technology and requires freedom from up to down structure. As a consequence, strategy mapping and structure within the organization create the technological empowerment, thereby drive innovation, that would lead to the organization success.

As effort to verify if these matters to top management, a semi-structured interview was conducted with three managers. Also, twenty questionnaires were distributed and collected from employees of Vodafone. The interview validation was a mixed report but the managers agreed that strategy and structure are very important element, but management style is the key platform to build to achieve innovation. There viewpoint is in line with the literature review. While, questionnaires distributed to the employees attracted higher answers on issues such as higher pay and can-do-attitude, including management strategy and structure as key to innovative solutions. The employees demonstrated that higher pay could lead to innovative output.

It is the responsibility of the management through its strategy and structure to harness the employees conscious and unconscious output, with a well coordinated, flexible and functional systems. 


\section{REFERENCES}

1. Ajen, I. and Fishbein M. (1980) Understanding attitudes and Predicting Social Behaviour: Pearson Prentice Hall

2. Bernanke, B. S. and Frank, R. H. (2009) Principles of Economics: 4th Ed.: McGraw-Hill Irwin, USA

3. Chandler, A. D. (1962/1998) Strategy and Structure: MIT Press: Cambridge, USA

4. Chandler, A. D. (1990) Scale and Scope: The Dynamics of Industrial Enterprise: Harvard University Press: USA

5. Cooke, P. and Morgan, K. (1998) The Associational Economy: Firms, Regions, and Innovation: Oxford University Press: England

6. Flamm, K. (1988) Creating the Computer: Government, Industry, and High-Technology: Brookings Institution, USA

7. Harrison, L. E. and Huntington, S. P. (2000) Culture Matters: Basic Books, USA

8. Hoecklin, L. (1997) Managing Cultural Differences. Strategies for Competitive Advantage: Pearson Edu. Ltd.: England

9. Hofstede, G., (1980) Culture's consequences, international differences in work-related values: Sage: Newbury Park, USA.

10. Hofstede, G., (1991) Cultures and organizations, software of the mind: McGraw-Hill Irwin, USA

11. Hofstede, G., Bond, M. H., (1988) the Confucius Connection, From Cultural Roots to Economic Growth: McGraw-Hill Irwin, USA

12. Jankowicz, A. D. (2005) Business Research Projects: 4th Ed.: Thomson Learning: London England

13. Johnson, G. et al (2008) Exploring Corporate Strategy: 8th Ed.: Pearson Education Limited: England

14. Kirton, G. and Greene, A M. (2005) The Dynamics of Managing Diversity. A critical Approach: 2nd Ed.: Elsevier Butterworth-Heinemann: England

15. Lawrence, H. E., (2002) Culture matters, how values shape human progress: Basic Books, USA.

16. Lazonick, W. (1990) Competitive Advantage of the Shop Floor: Harvard University Press, USA

17. Lam, A. (2000) "Tacit knowledge, Organizational Learning, Societal Institutions: an Integrated Framework", Organization Studies 21, pp. 487-513.

18. Lam, A. (2002) "Alternative Societal Models of Learning and Innovation in the Knowledge Economy”, International Social Science Journal 17, pp. 67-82.

19. Mintzberg, H. (1979) The Structuring of Organization: Prentice Hall, USA

20. Mullins, L. J. (2010) Management and Organizational Behaviour: 9th Ed.: Pearson Prentice Hall, USA

21. Newstrom, J. W. and Keith, D. (1993) Organizational Behaviour - Human Behaviour at Work: Graw-Hill Irwin, USA

22. Rugman, A., and Collinson, S. (2009) International Business: 5th Ed.: Pearson Prentice Hall: U.S.A.

23. Schneider, S. C. and Barsoux, J L. (2003) Managing Across Cultures: 2nd Ed.: Pearson Prentice Hall, USA

24. Schumpeter, J. (1911) The Theory of Economic Development: Harvard University Press, USA

25. Storey, J. (2001) Cultural Theory and Popular Culture. Pearson Education Ltd, England

26. Taylor Cox, Jr. (1994) Cultural Diversity in Organizations: Berrett-Koehler Publishers, Inc. USA 